\title{
Evaluation of lightning protection systems proposed for small structures by electromagnetic simulation
}

\begin{abstract}
This paper validates the performance of low-cost lightning protection systems for small structures proposed by researchers in the past. Such structures have an acute demand in the countries with very high lightning ground flash density, yet the affordability of the mass public is quite limited due to the struggling economies of the countries. The protection systems for small housing structure, and a standalone protection structure for one or few people have been investigated by implementing the structures in HFSS/ANSYS software which employs finite element method. By applying current waveforms to represent first negative return stroke, subsequent negative return stroke and positive return stroke, the electric field and potential gradient of the entire space and the current density and the thermal profile of the protective structure have been computed. The objectives were to find whether the voltage distribution in the wake of a lightning strike could initiate side flashes, generate touch potential and step potentials that exceed dangerous levels, drive current densities due to which the structure collapse under thermal effects. It has been found that the proposed protective structures could suppress side flashes and harmful effects due to step potential while the structure will be able to withstand the heat generated. However, the touch potential could still be beyond the human injury thresholds, thus a minimum separation from the lightning current passage should be advised to the occupants.
\end{abstract}

Keyword: ANSYS; Potential gradient; Side flash; Small strctures 